\title{
RANCANG BANGUN SISTEM KEAMANAN SEPEDA MOTOR BERBASIS IOT (INTERNET OF THINGS)
}

\author{
Irma Salamah ${ }^{1)}$, Ahmad Taqwa ${ }^{2)}$, Adi Tri Wibowo ${ }^{3)}$ \\ ${ }^{1}$ Jurusan Teknik Elektro, Program Studi Teknik Telekomunikasi D IV, Politeknik Negeri Sriwijaya \\ email : irma.salamah@yahoo.com \\ ${ }^{2}$ Jurusan Teknik Elektro, Program Studi Teknik Telekomunikasi D IV, Politeknik Negeri Sriwijaya \\ email : a taqwa@yahoo.com \\ ${ }^{3}$ Jurusan Teknik Elektro, Program Studi Teknik Telekomunikasi D IV, Politeknik Negeri Sriwijaya \\ email : aditriwibowo30@gmail.com
}

\begin{abstract}
Motorcycle are the most common transportation used by public to go to a nearby or distant places. Besides the price is relatively cheap, motorcycle can be used to bypassing traffic jam or narrow road. Motorcycle are tend to be a target of thievery due to weak surveillance of vehicles. Unlike cars which have more effective safety system like GPS (Global Positioning System), motorcycle only have a conventional yet less effective safety system, such as safety locks. This research will design a motorcycle safety system that combines microcontrollers with Android applications. The microcontroller used is the Arduino Mega 2560 equipped with GPS modules, SIM900 modules and relays. Application of IOT (Internet of Thing) technology as a medium used for communication between Android tools and applications. The GPS module will provide the coordinates of the motorcycle position and displayed in the Android application via Internet communication using the SIM900 module. The Relay is designed to disconnect the power stream on the vehicle machine. Based on the results of this design can be implemented on the motorcycle to be able to know the position of the stolen vehicle.
\end{abstract}

Keywords : Arduino Mega, GPS, SIM900, Internet of Things, Android

\begin{abstract}
Abstrak
Sepeda motor merupakan transportasi pribadi yang paling banyak digunakan masyarakat untuk pergi ke tempat yang dekat bahkan jauh sekalipun. Disamping harganya yang tergolong mudah dijangkau, sepeda motor lebih mudah untuk melalui kemacetan dan jalan sempit sekalipun. Sepeda motor seringkali menjadi target pencurian dikarenakan lemahnya pengawasan terhadap kendaraan. Umumnya sepeda motor hanya memiliki keamanan seperti kunci pengaman konvensional, berbeda dengan kendaraan seperti mobil yang memiliki perangkat GPS (Global Positioning System). Pada penelitian ini dibuatlah rancang bangun sistem keamanan sepeda motor yang menggabungkan mikrokontroler dengan aplikasi android. Mikrokontroler yang digunakan adalah Arduino Mega 2560 yang dilengkapi dengan modul GPS, modul SIM900 dan relay. Penerapan teknologi IOT (Internet of Thing) sebagai media yang digunakan untuk komunikasi antara alat dan aplikasi android. Modul GPS akan memberikan koordinat posisi sepeda motor dan ditampilkan pada aplikasi android melalui komunikasi internet menggunakan modul SIM900. Relay dirancang untuk memutus aliran listrik pada mesin kendaraan. Berdasarkan hasil dari rancang bangun ini nantinya dapat diimplementasikan pada sepeda motor untuk dapat mengetahui posisi kendaraan yang telah dicuri.
\end{abstract}

Keywords : Arduino Mega, GPS, SIM900, Internet of Things, Android 


\section{PENDAHULUAN}

Meningkatnya jumlah kendaraan sepeda motor dewasa ini merupakan salah satu faktor penyebab maraknya kejahatan pencurian sepeda motor. Disamping itu sepeda motor biasanya memiliki tingkat pengawasan dan keamanan yang masih sangat rentan untuk dicuri. Berbeda dengan kendaran mobil yang telah dilengkapi GPS, sepeda motor masih menggunakan kunci keamanan konvensional yang masih sangat rentan untuk dirusak. Dalam pencarian sepeda motor yang dicuri pastinya akan sangat sulit untuk ditemukan mengingat minimnya petunjuk lokasi sepeda motor sekarang [1].

Pemanfaatan teknologi IoT (Internet of Thing) dan teknologi GPS (Global Positioning System) yang dikoneksikan dengan aplikasi android pada sistem keamanan sepeda motor akan memudahkan mengetahui posisi sepeda motor yang telah dicuri. Posisi sepeda motor akan ditampilkan dalam visual google maps, yang akan memudahkan dalam pencarian. Selain itu aplikasi yang dibuat dilengkapi dengan fitur untuk mengontrol status sepeda motor hidup atau mati, sehingga secara keseluruhan sistem alat yang akan dibangun dapat membantu mematikan mesin sepeda motor dari jarak jauh ketika terjadi kehilangan [2]. Keamanan ini merupakan solusi terbaik dalam mengetahui posisi kendaraan yang telah dicuri.

Tujuan penelitian yaitu membuat rancang bangun sebuah sistem keamanan untuk mengetahui posisi kendaraan dan mengontrolnya dari jarak jauh menggunkan aplikasi android. Pada aplikasi dapat menampilkan posisi sepeda motor dan memutus aliran listrik pada mesin sepeda motor. kombinasi antara perangkat keras dan perangkat lunak ini diharapkan dapat menciptakan suatu sistem keamanan ganda dan pengawasan pada sepeda motor [3][4].

\section{GPS (GLOBAL POSITIONING SYSTEM)}

GPS (Global Positioning System) adalah sistem yang menentukan letak dipermukaan bumi dengan bantuan penyelarasan (synchronization) sinyal satelit[5]. GPS merupakan sistem navigasi yang memiliki lebih dari 24 satelit atau tepatnya 31 satelit yang mengirimkan sinyal gelombang mikro yang diterima oleh antenna perangkat GPS untuk menentukan lokasi [6]. Sistem GPS memiliki tiga segmen yaitu Satelit (Space Segment), pengendali (Control Segment), dan penerima atau pengguna (User Segment)[7].

\section{ARDUINO}

Arduino adalah pengendali mikro single-board yang bersifat open-source, dirancang untuk memudahkan pengguna elektronik dalam berbagai bidang [8]. Bahasa C merupakan Bahasa yang digunakan dalam pemrograman Arduino. Untuk memprogram board Arduino, maka diperlukan software Arduino IDE (Integrated Development Enviroment). Arduino IDE merupakan software open-source sehingga dapat di download secara gratis.

\section{IOT (INTERNET OF THINGS)}

IoT (Internet of Things) merupakan sebuah konsep yang memiliki tujuan untuk memperluas manfaat dari konektivitas internet yang tersambung secara terusmenerus. Pada dasarnya, IOT mengacu pada benda yang dapat diidentifikasikan secara unik sebagai representasi virtual dalam struktur berbasis internet [6].

\section{ANDROID}

Android adalah sebuah sistem operasi untuk perangkat mobile berbasis linux yang mencakup sistem operasi, middleware dan aplikasi, android menyediakan platform terbuka bagi para pengembang untuk menciptakan aplikasi mereka (Safaat, 2012) [9]. 


\section{METODE PENELITIAN}

\section{Perancangan Perangkat}

Perancangan perangkat dalam penelitian dibagi menjadi dua bagian yaitu perancangan perangkat keras (hardware) dan perancangan perangkat lunak (software). Perancangan perangkat diawali dengan perancangan blok diagram secara keseluruhan. Dari blok diagram tersebut, dapat diketahui sistem kerja rangkaian secara keseluruhan. Blok diagram tersebut dapat menghasilkan suatu sistem yang berguna untuk mencapai suatu tujuan tertentu.

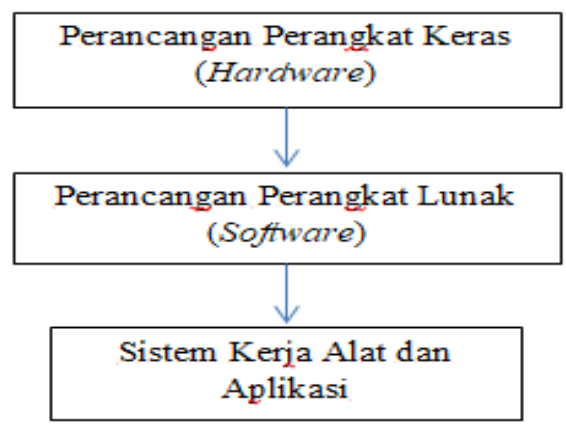

Gambar 1. Tahap perancangan perangkat

\section{Perancangan Perangkat Keras (Hardware) \\ Perancangan perangkat keras} (hardware) merupakan perancangan alat yang akan dibuat. Pada perancangan alat haruslah diperhatikan dalam dalam pemasangan komponen komponen yang dibutukan untuk membuat alat. Dengan memperhatikan karakteristik pada komponen dapat mengurangi terjadinya kesalahan dalam perancangan.

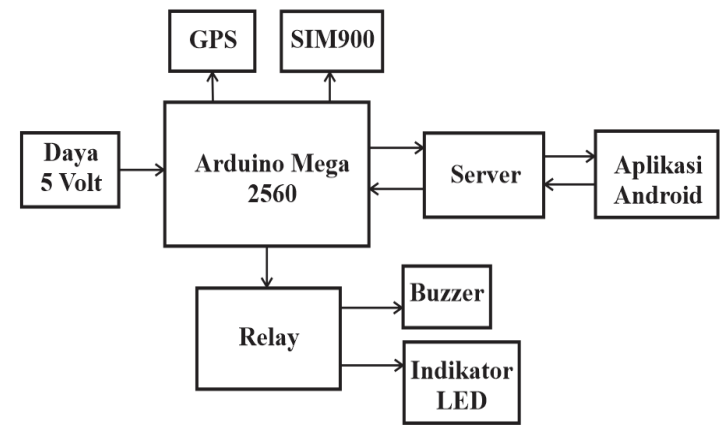

Gambar 2. Blok Diagram Perancangan Perangkat Keras (Hardware)

\section{Arduino Mega}

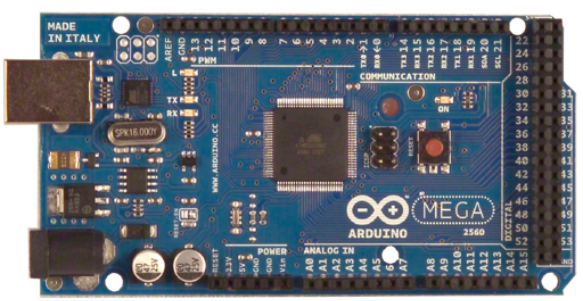

Gambar 3. Arduino Mega 2560

Arduino Mega 2560 adalah mikrokontroller yang berbasis Arduino dengan menggunakan chip ATmega2560. Pada board memiliki 54 buah pin digital $\mathrm{I} / \mathrm{O}, 15$ pin diantaranya adalah PWM, 16 pin analog input, 4 pin UART (serial port hardware). Arduino Mega 2560 dilengkapi dengan sebuah port USB, sebuah oscillator $16 \mathrm{MHz}$, ICSP header, power jack DC, dan tombol reset [10]. Untuk segala sesuatu yang dibutuhkan untuk sebuah mikrokontroller, Arduino Mega 2560 sudah termasuk lengkap untuk itu.

\section{Modul GPS Ublox Neo-6M}

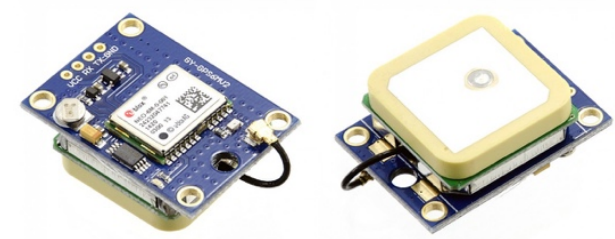

Gambar 4. Modul GPS Ublox Neo-6M 
Mesin u-blox NEO-6M GPS pada modulmodul ini cukup bagus, dan juga memiliki sensitivitas tinggi untuk aplikasi dalam ruangan. Selain itu, ada satu baterai isi ulang yang kompatibel dengan MS621FE untuk cadangan dan EEPROM untuk menyimpan pengaturan konfigurasi. Modul NEO-6M GPS bekerja dengan baik dengan kisaran 3,3 sampai 5 Volt pada input DC. Modul NEO6M mencakup satu antarmuka UART yang dapat dikonfigurasi untuk komunikasi serial, tetapi memiliki default baud rate UART (TTL) yaitu 9,600.

Modul SIM900

Gambar 5. Modul SIM900

Modul SIM900 merupakan modul GSM / GPRS, digunakan di banyak ponsel dan PDA. Modul ini juga dapat digunakan untuk mengembangkan IOT (Internet of Things) dan Aplikasi Tertanam. SIM900 adalah mesin dual-band GSM / GPRS yang bekerja pada frekuensi EGSM $900 \mathrm{MHz}$ dan DCS 1800MHz. SIM900 memiliki fitur GPRS multi-slot kelas $10 /$ kelas 8 (opsional) dan mendukung skema pengkodean GPRS CS-1, CS-2, CS-3 dan CS-4.

\section{Relay 4 channel 5 volt}

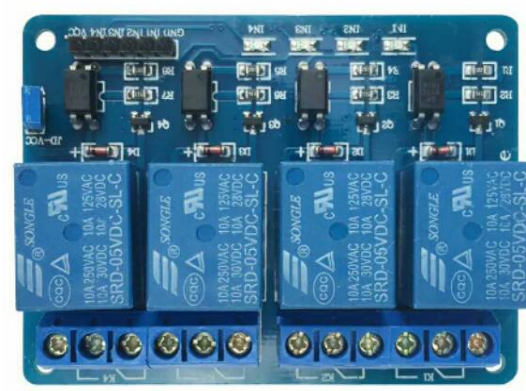

Gambar 6. Relay 4 channel 5 volt

Relay merupakan salah satu komponen output / keluaran yang dapat digunakan pada peralatan elektronik[11]. Modul 4 Saluran Relay adalah papan yang nyaman yang dapat digunakan untuk mengontrol tegangan tinggi, beban arus tinggi seperti motor, katup solenoid, lampu dan beban AC. Dirancang seperti ini untuk memudahkan berinterkasi dengan mikrokontroler seperti Arduin, PIC dan lain-lain. Terminal relay (COM, NO dan $\mathrm{NC}$ ) sedang dibawa keluar dengan terminal sekrup. Itu juga dilengkapi dengan LED untuk menunjukkan status relay.

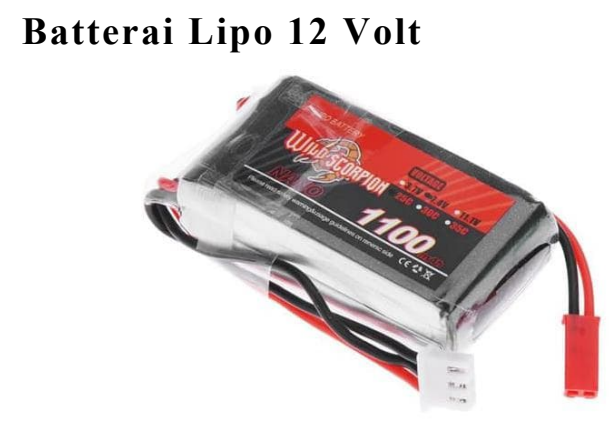

Gambar 7. Batterai Lipo 12 Volt

Batterai Lipo merupakan salah satu jenis baterai yang sering digunakan dalam dunia RC. Ratio Power to Weight yang memungkinkan baterai dicetak sesuai dengan keinginan merupakan keunggulan utama dari baterai [12]. 


\section{Ubec Stepdown 5 Volt}

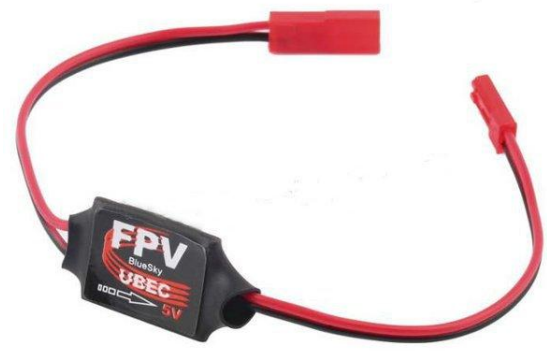

Gambar 8. Ubec Stepdown 5 Volt

Ubec stepdown 5 volt merupakan sirkuit elektronika yang dirancang untuk dapat menurunkan tegangan 12 volt dari keluaran baterai menjadi 5 volt [13].

\section{Perancangan Perangkat Lunak (Software)}

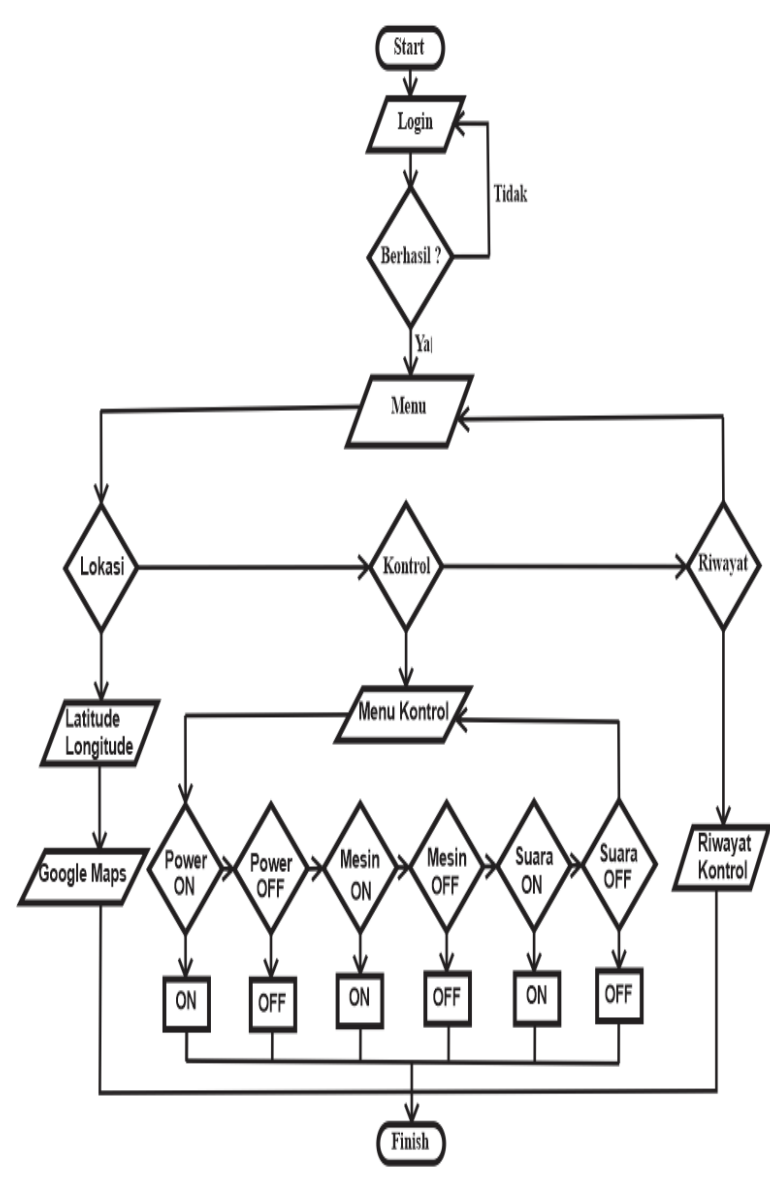

Gambar 9. Flowchart Perancangan Perangkat Lunak (Software)

Flowchart perancangan perangkat lunak (software) menjelaskan bahwa sistem kerja perangkat lunak (software) dimulai dengan melakukan login, ketika login berhasil maka aplikasi akan menampilkan tampilan menu dan apabila login tidak berhasil maka aplikasi tidak akan berpindah ke tampilan menu. Pada bagian menu utama terdapat tiga bagian yaitu lokasi, control dan riwayat. Lokasi adalah tampilan untuk melihat koordinat posisi sepeda motor dan nantinya dapat dilihat dala visual google maps. Kontrol adalah tampilan untuk memberikan perintah pada sepeda motor pada aplikasi, dapat memutus aliran listrik sepeda motor dan memberikan suara 
keras seperti suara klakson sepeda motor. Riwayat adalah tampilan untuk melihat kondisi terakhir sepeda motor pada saat dikontrol.

\section{Sistem Kerja Alat dan Aplikasi}

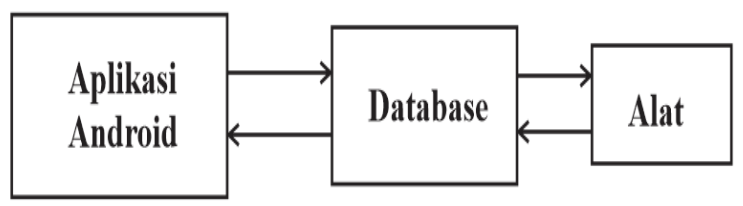

Gambar 10. Diagram blok sistem kerja hardware dan software

Diagram blok sistem kerja alat dan aplikasi menunjukan bahwa perintah yang dilakukan pada aplikasi android akan dikirimkan ke database yang nantinya akan dibaca oleh alat dan melakukan perintah yang dikirimkan aplikasi. Dan sebaliknya pada alat akan mengirimkan data yang akan masuk ke database dan akan diterima oleh aplikasi yang nantinya dapat mengetahui koordinat posisi sepeda motor.

\section{HASIL DAN PEMBAHASAN}

Pada bagian ini menjelaskan hasil dari perancangan perangkat keras (hardware) dalam bentuk alat dan perancangan perangkat lunak (software) berupa aplikasi.

\section{Tampilan Alat}

Tampilan alat sistem keamanan sepeda motor secara otomatis telah dirancang sesuai dengan blok diagram perancangan perangkat keras (hardware) yang mana pada alat tersebut diberikan indikator LED yang dibuat untuk kondisi mesin kendaran.

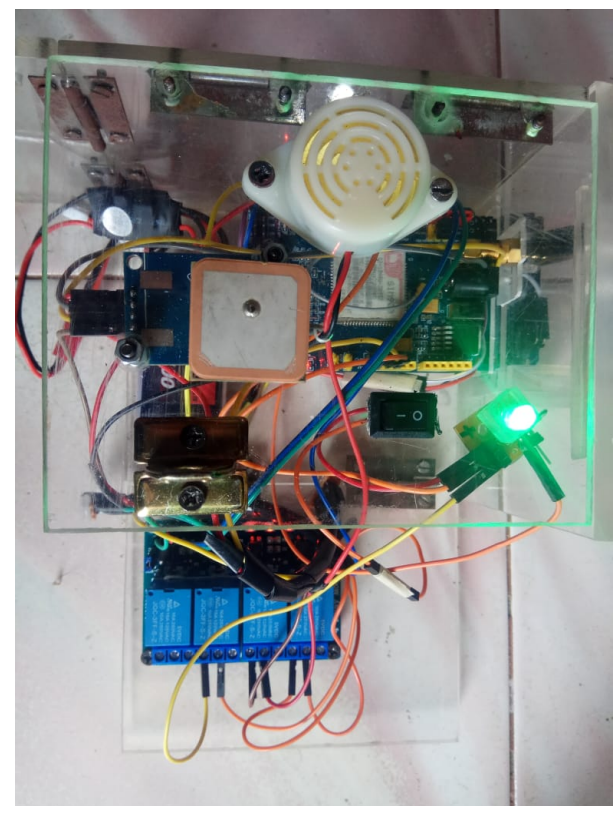

Gambar 11. Tampilan Alat Status Mesin On

Gambar 11. menunjukan indikator LED dalam keadaan hidup yang menandakan bahwa relay mesin sepeda motor dalam status on.

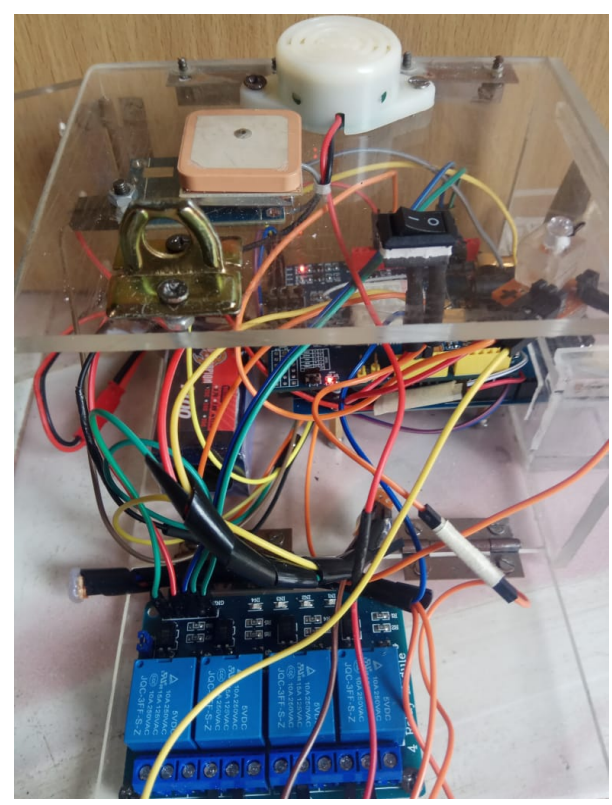

Gambar 12. Tampilan Alat Status Mesin Off 
Gambar 12. menunjukan indikator LED dalam keadaan mati yang menandakan bahwa relay mesin sepeda motor dalam status off.

\section{Tampilan Aplikasi}

Tampilan pada aplikasi sistem keamanan sepeda motor ini berupa aplikasi smartphone android yang mana pada aplikasi tersebut terdapat beberapa menu seperti login, menu utama, posisi sepeda motor, menu kontrol, dan riwayat.

\section{SECURITY MOTOR}

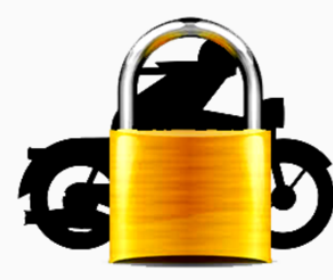

$\therefore$ Isername

a Password

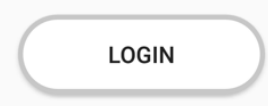

Gambar 13. Tampilan Login

\section{SECURITY MOTOR}
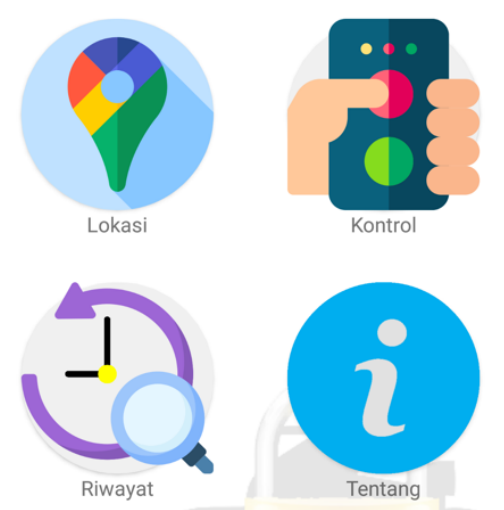

Gambar 14. Tampilan Menu Utama

\section{LOKASI}

2020-07-28 10:34:59

latitude $\quad-2.98649910$

longitude 104.73523000

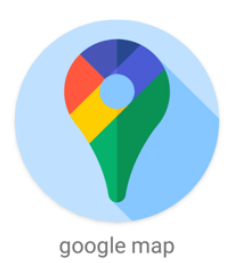

Gambar 15. Tampilan posisi sepeda motor 
Gambar 15. tampilan aplikasi yang menampilkan latitude dan longitude sepeda motor yang dapat ditampilkan pada google maps dengan menekan icon google maps.

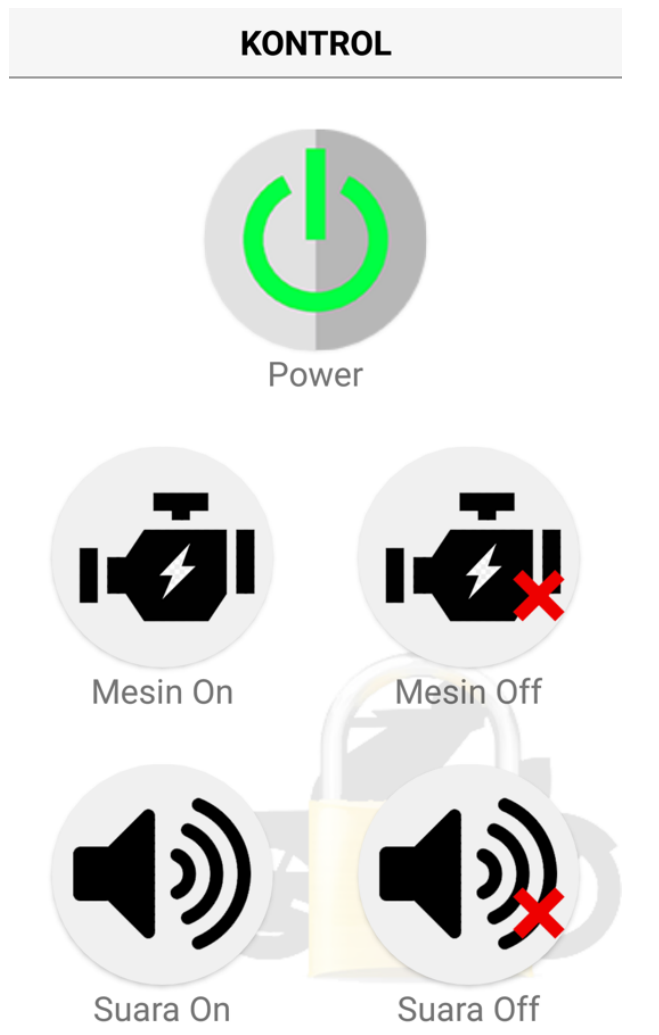

Gambar 16. Tampilan Menu Kontrol

Gambar 16. tampilan aplikasi yang menampikan menu kontrol yang mana dapat memutuskan mesin sepeda motor dan juga memberikan suara keras seperti suara klakson sepeda motor.

\begin{tabular}{ccc}
\multicolumn{3}{l}{ Riwayat Kontrol } \\
\hline RELAY & STATUS & WAKTU \\
POWER & OFF & $2020-07-29$ \\
& & $18: 11: 07$ \\
POWER & ON & $2020-07-29$ \\
& & $18: 11: 05$ \\
MESIN & OFF & $2020-07-29$ \\
& & $18: 11: 03$ \\
MESIN & ON & $2020-07-29$ \\
& & $18: 11: 01$ \\
SUARA & OFF & $2020-07-29$ \\
& & $18: 11: 00$ \\
SUARA & ON & $2020-07-29$ \\
& & $18: 10: 57$ \\
POWER & OFF & $2020-07-29$ \\
& & $18: 04: 08$ \\
POWER & ON & $2020-07-29$
\end{tabular}

Gambar 17. Tampilan Riwayat Kontrol

Tabel 1. Pengujian pada alat untuk memperbarui pembacaan lokasi kendaraan pada aplikasi android

\begin{tabular}{|l|l|l|l|}
\hline \multirow{2}{*}{$\begin{array}{l}\text { Data } \\
\text { masuk } \\
\text { ke- }\end{array}$} & \multicolumn{2}{|l|}{ Posisi Kendaraan } & $\begin{array}{l}\text { Waktu } \\
\text { data } \\
\text { masuk } \\
(\mathrm{s})\end{array}$ \\
\hline 1 & Latitude & Longitude & \\
\hline 2 & -2.973998 & 104.719100 & 27,08 \\
\hline 3 & -2.974110 & 104.719146 & 26,61 \\
\hline 4 & -2.974120 & 104.719131 & 28,52 \\
\hline 5 & -2.974146 & 104.719154 & 29,04 \\
\hline 6 & -2.974118 & 104.719154 & 26,84 \\
\hline 7 & -2.974092 & 104.719116 & 27,56 \\
\hline 8 & -2.974090 & 104.719108 & 27,63 \\
\hline 9 & -2.974136 & 104.719139 & 28,12 \\
\hline 10 & -2.974112 & 104.719146 & 27,32 \\
\hline
\end{tabular}

Berdasarkan hasil pengujian table 1, pembacan koordinat modul GPS yang 
dikirimkan ke database oleh alat ke aplikasi yaitu memiliki waktu rata-rata 27,603 detik.

Tabel 2. Pengujian pada kontrol pada aplikasi untuk respon ke alat

\begin{tabular}{|l|l|l|l|l|}
\hline Percobaan & Status & \multicolumn{3}{|c|}{ Waktu respon (s) } \\
\cline { 3 - 5 } ke- & Relay & Power & Mesin & Suara \\
\hline 1 & ON & 13,04 & 22,36 & 15,42 \\
\hline 2 & ON & 16,53 & 19,82 & 22,12 \\
\hline 3 & ON & 14,96 & 14,75 & 12,01 \\
\hline 4 & ON & 18,56 & 10,98 & 12,91 \\
\hline 5 & ON & 10,30 & 13,43 & 18,45 \\
\hline 6 & OFF & 11,95 & 11,25 & 20,63 \\
\hline 7 & OFF & 15,55 & 18,67 & 14,72 \\
\hline 8 & OFF & 18,04 & 19,78 & 16,44 \\
\hline 9 & OFF & 12,39 & 17,53 & 13,51 \\
\hline 10 & OFF & 12,53 & 16,72 & 13,24 \\
\hline
\end{tabular}

Berdasarkan hasil percobaan table 2 diatas dengan melakukan 30 pengujian, pada setiap relay masing masing 10 pengujian didapat rata-rata respon yaitu 15,1 detik

\section{SIMPULAN DAN SARAN}

Berdasarkan hasil rancang bangun sistem keamanan sepeda motor berbasis aplikasi android, maka diperoleh beberapa kesimpulan yaitu :

1. Dengan menggunakan sistem keamanan sepeda motor berbasis aplikasi android ini dapat memudahkan dalam mengetahui posisi kendaraan yang telah dicuri

2. sistem dapat bekerja dengan baik dalam mengendalikan relay yaitu dapat memutus dan menghubungkan aliran listrik pada mesin sepeda motor dengan control jarak jauh menggunkan aplikasi android

3. Sistem dapat memperbarui titik koordinat sepeda motor dengan rata rata waktu 27,603 detik dari mengirim data ke server hingga ditampilkan pada aplikasi android

4. Waktu rata rata respon alat setelah mendapatkan perintah ON maupun OFF pada aplikasi yaitu 15,1 detik
Adapun beberapa saran untuk melakukan pengembangan sistem keamana sepeda motor adalah :

1. Pada pengembangan selanjutnya, diharapkan alat dapat dibuat lebih kecil menjadi satu board dengan rangkaian sesederhana mungkin.

2. Sebaiknya menggunakan mikrokontroler dan modul GSM yang lebih baik lagi agar mengirim dan menerima data tidak terjadi delay.

3. Pada pengimplementasian, alat sebaiknya diletakan serahasia mungkin dan ditempatkan pada tembat yang yang tidak mudah terkena air.

\section{TERIMA KASIH}

Terima kasih kepada kedua orang tua yang telah memberikan dukungan dan doa kepada penulis. Serta semua pihak yang telah membantu dalam penelitian yang tidak bisa disebutkan satu persatu.

\section{DAFTAR PUSTAKA}

[1] Wahyulianto, Rizal. (2019). SISTEM TRACKING KENDARAAN DENGAN MIKROKONTROLER BERBASIS WEB. Program Studi Teknik Informatika Fakultas Teknik Informasi dan Elektro, Universitas Teknologi Yogyakarta.

[2] Affrilianto, Rian. Dkk. (2017). RANCANG BANGUN SISTEM PELACAK KENDARAAN BERMOTOR MENGGUNAKAN GPS DENGAN ANTARMUKA WEBSITE. Jurnal Coding Sistem Komputer Untan. Volume 05, No.3

[3] Nurhartono, Agus (2015). Perancangan Sistem Keamanan untu Mengetahui Posisi Kendaraan Yang Hilang Berbasis GPS Dan Ditampilkan Dengan Smartphone

[4] NN Styanto. Dkk. (2019). Rancang sistem keamanan dan pengawasan pada kendaraan 
bermotor berbasis android. Universitas Muhammadiyah Surakarta

[5] Lhaksamana, K Muslim. (2018). APLIKASI INTERNET OF THINGS UNTUK PENGENDALI DAN PEMANTAU KENDARAAN. Fakultas Informatika, Program Studi S1 Ilmu Komputasi, Universitas Telkom. e-Proceeding of Engeenering : Vol.5, No.1

[6] Widjaya, Ady, Dkk. (2018). IMPLEMENTASI PERANGKAT IOT (INTERNET OF THINGS) SEBAGAI SISTEM PEMANTAU DAN PENGENDALI KENDARAAN. Sistem Informasi, Fakultas Teknologi Informasi, Universitas Budi Luhur.

[7] Saputra, Oka Kurniawan. Dkk. (2017). Rancang Bangun Sistem Keamanan Kendaraan Bermotor Berbasis GPS (Global Positioning System) dan Koneksi Bluetooth. Jurusan Teknik Elektro, Universitas Lampung, Bandar Lampung.

[8] Satrianto, F Wahyu, Dkk. (2016). SISTEM KEAMANAN BERBASIS ANDROID VEHICLE TRACKING DENGAN MIKROKONTROLER. Fakultas Teknik Elektro, Universitas Telkom. eProceeding of Engineering : Vol.3, No.1

[9] Fredy, Dkk. 2018. PERANCANGAN SISTEM MONITORING SEPEDA MOTOR MENGGUNKAKAN MODUL GPS BERBASIS ANDROID. e-Proceeding of Engineering: Vol.5, No.3

[10] microcontroller board. Mega-2560 Datasheet.https://datasheetspdf.com/pdf/1401 943/Arduino/Mega-2560 (diakses tanggal 12 Juli 2020)

[11] Susanti, Erma (2016). PENGEMBANGAN SISTEM PEMANTAU DAN PENGENDALI KENDARAAN MENGGUNAKAN RASPBERRY PI DAN
FIREBASE. Jurusan Teknik Informatika, Fakultas Teknologi Industri, IST AKPRIND, Yogyakarta.

[12] Angga. (2017). Panduan Praktis Cara Menggunakan Baterai Lipo. http://buayainstrument.com/blog-buaya-instrument/caramenggunakan-baterai-lipo (diakses tanggal 20 Juli 2020)

[13] UBEC DC-DC Converter Step Down Module 3A 5V For RC Plane FPV. https://www.jakartanotebook.com/ubec-dcdc-converter-step-down-module-3a-5v-for-rcplane-fpv-black-or-red (diakses tanggal 20 Juli 2020) 